Disponível em

http://www.anpad.org.br/rac

RAC, Rio de Janeiro, v. 18, n. 3, art. 5, pp. 328-350, Maio/Jun. 2014

\title{
Percepções de Valor e Elementos Estruturantes das Microfranquias
}

\author{
Microfranchising Value Perception and Structural Elements
}

Pedro Lucas de Resende Melo

E-mail: resendemelo@usp.br

Universidade Paulista - UNIP

Rua Dr. Bacelar, 1212, Vila Clementino, 04026-002, São Paulo, SP, Brasil.

Felipe Mendes Borini

E-mail: fborini@espm.br Escola Superior de Propaganda e Marketing - ESPM Rua Dr. Álvaro Alvim, 123, Vila Mariana, 04018-010, São Paulo, SP, Brasil.

Julio Araujo Carneiro da Cunha E-mail: juliocunha@uninove.br Universidade Nove de Julho - UNINOVE Av. Francisco Matarazzo, 612, 05001-100, São Paulo, SP, Brasil. 


\title{
Resumo
}

As microfranquias são franquias que requerem o investimento de até R\$ 50 mil. Há atualmente 336 redes de franquias que operam nesse formato no Brasil. A importância desse tipo de negócio se justifica pelo crescimento do poder aquisitivo das classes de menor renda. Entretanto, trata-se de um modelo de franquias com carência de estudos. O objetivo deste artigo está fundamentado em identificar se existem diferenças entre as microfranquias e as franquias convencionais diante dos elementos estruturantes do sistema de franchising. Isso significa avaliar se as franquias convencionais se diferenciam das microfranquias quanto à percepção de valor do suporte pelo franqueado e a percepção de valor da marca pelo mesmo. Foram analisadas um total de 1090 redes de franquias convencionais e redes de franquias que operaram por microfranquias, de acordo com dados editados no período de 2007 a 2012. Adicionalmente, realizaram-se três estudos de casos com microfranqueados. A técnica da regressão OLS comprovou que há diferenças na percepção de valor quanto à marca da rede de franquias, e que não há diferenças na percepção do suporte ao franqueado.

Palavras-chave: franquias; empreendedorismo; microempreendedor.

\begin{abstract}
A microfranchise requires investment of up to $\mathrm{R} \$ 50$ mil. There are currently 336 franchise chains operating in this format in Brazil. The importance of this type of business is justified by lower income classes' increased purchasing power. However, it is a franchise model that has not been extensively studied. The purpose of this article is to identify whether there are differences between conventional franchises and microfranchises related to value perception and structural elements of the franchise system. This means assessing whether conventional franchises differ from microfranchises in regards to franchisees' perception of support value and perceived brand value. We analyzed 1090 conventional chains and chains which operated through microfranchising using data published during the period 2007-2012. Additionally, we performed three case studies with microfranchisees. OLS regression showed that there are differences in the perception of franchise brand value and but not in the perception of support to the franchisee.
\end{abstract}

Key words: franchising; entrepreneurship; microentrepreneur. 


\section{Introdução}

Dentro do modelo de negócios de franchising, presenciou-se, na última década, o surgimento das microfranquias. Diversas redes de franquias de vanguarda e redes iniciantes têm moldado esse tipo de franquia, dado que é um modelo que requer baixo investimento e conta com a possibilidade de financiamento para a sua aquisição pela classe média emergente. Trata-se de franquias de até $\mathrm{R} \$ 50$ mil, incluídos o capital para a instalação, a taxa de franquia e o capital de giro (Associação Brasileira de Franchising $[\mathrm{ABF}], 2013)$. Parâmetros internacionais compreendem as microfranquias como empreendimentos que envolvem investimentos até US\$25 mil. De maneira geral, estas microfranquias estão situadas no segmento de serviços, muitas vezes não necessitando de ponto comercial, nas quais o próprio franqueado é o principal operador, requerendo poucos ou mesmo nenhum funcionário (Fairbourne, Gibson, \& Dyer, 2007).

A importância desse tipo de negócio se justifica pelo crescimento do poder aquisitivo das classes de menor renda e carente (Fairbourne, 2006; Illetschko, 2011; Munoz, Alon, \& Mitchell, 2010), em especial nos mercados emergentes. Especificamente na situação brasileira, as microfranquias estão direcionadas prioritariamente para os emergentes à nova classe C (ABF, 2013). Essas classes correspondem a 53\% da população brasileira, isto é, cerca de 98 milhões de pessoas (Luce, 2013; Neri, 2008), concentrando 46,6\% do poder de compra de consumo do país (Neri, 2011).

De acordo com dados da Associação Brasileira de Franchising (2013), há, atualmente, 12.561 unidades franqueadas no formato micro, sendo 336 redes de franquias que operam no formato de microfranquias, o que representa cerca de $17 \%$ do total das redes em operação no Brasil e $4 \%$ do faturamento dentre elas, ou seja, mais de $\mathrm{R} \$ 3,7$ bi/anuais. Esses números não são apenas representativos, mas são também crescentes, de forma que os dados mais recentes demonstram um crescimento de $36 \%$ no número de redes desse formato nos últimos dois anos.

No entanto, ainda que o modelo de negócios tenha sua importância constatada nos números nacionais apresentados, esse fenômeno recente ainda carece de respaldo acadêmico para sua compreensão. O marco inicial sobre as microfranquias ocorreu com a publicação do artigo seminal de Fairbourne (2006), apresentando as microfranquias como um modelo de negócios para a criação de riquezas para a base da pirâmide em países pobres. Tais aspectos foram um pouco mais aprofundados por Fairbourne, Gibson e Dyer (2007), por meio de uma coletânea sobre microfranquias. Em seguida, Ivins (2008) investigou a inserção de microfranquias como instrumento para a expansão de escolas em áreas remotas no Nepal. Na linha de pensamento que entende esse modelo de negócio como uma possível solução para os problemas das classes sociais da base da pirâmide, Oduor, Kamau e Mathenge (2009) analisaram as microfranquias responsáveis pela distribuição de drogas antimaláricas no Quênia. Por sua vez, Nghia (2010) realizou uma breve revisão de literatura apresentando alternativas a se desenvolver para a redução da pobreza, sendo as microfranquias uma dessas alternativas.

Contudo, somente em dois estudos desenvolvidos por Burand e Koch (2010) e Kistruck, Webb, Sutter e Ireland (2011) notam-se os primeiros registros sobre a comparação das microfranquias com os modelos convencionais de franquias. No estudo de Burand e Koch (2010), tem-se uma discussão superficial, não havendo um aprofundamento teórico de grande robustez. Por seu turno, Kistruck et al. (2011) se baseiam em estudos de casos de microfranquias originárias do Quênia, dos Estados Unidos (em atuação em países pobres), da Índia, do Irã e da Guatemala, levando em consideração aspectos institucionais e econômicos destes países e sua influência para o êxito das microfranquias.

Logo, o crescimento no número de microfranquias associado à carência de estudos nessa área em relação às franquias convencionais é o principal motivador para a realização do presente artigo. Foi impossível identificar qualquer estudo veiculado em periódicos científicos sobre microfranchising no Brasil, seja na revisão de Melo e Andreassi (2010) sobre os estudos no segmento de franchising, assim como nos esforços realizados pelos autores do presente texto para atualizar os dados não cobertos no artigo mencionado. Além disso, percebe-se que os estudos internacionais mencionados anteriormente, 
que se iniciam a partir de 2007, concentram-se, sobretudo, na utilização de microfranquias em países subdesenvolvidos e em desenvolvimento como forma de inserção econômica da população ou como meio para redução de limitações dos serviços públicos e sociais. Isto é, os estudos não investigam as microfranquias sob a perspectiva econômica e administrativa com o intuito de comparar seu modelo de gestão com as franquias convencionais.

Diante da ausência de estudos comparativos entre as franquias convencionais e as microfranquias, duas suposições emergem. A primeira afirma ser desnecessário investigar as particularidades na gestão das microfranquias, pois, exceto pelo capital investido, elas não diferem em nada em relação às franquias convencionais. A segunda, oposta à primeira, propõe que as microfranquias tenham particularidades gerenciais que exigem uma investigação e atenção diferenciadas em relação às franquias convencionais. Essa última corrente é a que defendemos neste artigo.

Com isso, o objetivo deste artigo está fundamentado em identificar se existem, entre as microfranquias e franquias convencionais, diferenças na percepção de valor quanto aos elementos estruturantes do sistema de franchising. Isso significa avaliar se as franquias convencionais diferenciam-se das microfranquias quanto à percepção de valor do suporte pelo franqueado e a percepção de valor da marca pelo franqueado.

Pressupõe-se que, ao comparar a percepção de valor do suporte e da marca do franqueado, será possível discernir se é necessária uma gestão diferenciada para esses dois formatos de franquias. Caso as suposições propostas se comprovem em primeira instância, existe, neste artigo, uma importante contribuição gerencial, que é a necessidade de um modelo específico para a administração das redes de microfranquias. Consequentemente, esse resultado despontaria como uma contribuição significativa para os estudos do segmento de franchising, pois suportaria a premissa de que as microfranquias precisam ser compreendidas e estudadas de maneira distinta das franquias convencionais. Constatação essa que abriria um campo de investigação para o aprofundamento do conhecimento das estratégias organizacionais do segmento de franchising.

Dessa forma, para sustentar a argumentação, o artigo está estruturado da seguinte maneira: referencial teórico, hipóteses de pesquisa, metodologia de pesquisa, análise dos resultados, estudos de casos, discussão dos resultados e conclusões.

\section{Referencial Teórico}

\section{As microfranquias em uma perspectiva econômico-social}

As microfranquias são originárias em mercados que apresentam grande parcela da população localizada na base da pirâmide, possuindo o objetivo principal de reduzir a pobreza por meio de negócios baseados no sistema de franchising (Burand \& Koch, 2010). Para Kistruck et al. (2011), o fundamental sobre a definição do conceito de microfranquias é considerar que se trata de um modelo de negócio calcado no franchising e que possui o objetivo de gerar riquezas a fim de reduzir a pobreza.

Diferentemente das franquias puramente sociais que visam fornecer bens e serviços para populações pobres, as microfranquias podem constituir-se por negócios que não visam necessariamente atender a uma comunidade carente, ainda que sejam franquias destinadas a franqueados constituintes da base da pirâmide (Burand \& Koch, 2010). Seelos e Mair (2007) endossam essa afirmativa referente aos negócios voltados para a base da pirâmide. Da mesma forma que Prahalad (2004) já defendia que essa adaptação nos negócios para atender a base da pirâmide é capaz de criar novos mercados através do aumento da base de consumidores e propiciar o surgimento de empreendedores voltados a essa população. Todavia, mais do que as grandes multinacionais, as 
pequenas empresas estariam melhor capacitadas a operar localmente em mercados de base da pirâmide por conhecerem as especificidades de tal população (Karnani, 2006).

Nesta questão, emerge a importância das microfranquias, pois são empreendimentos desenvolvidos por empreendedores, não se referindo propriamente a grandes grupos empresariais ou mesmo multinacionais. No caso do segmento de franchising, notamos um redirecionamento na formatação dos seus negócios para a criação de empreendimentos que necessitam de investimento limitado às condições da base da pirâmide e à nova classe média emergente, como é o caso das microfranquias no Brasil.

Partindo dessas definição e contextualização, surge a proposição central da argumentação do presente artigo: o fato da microfranquia exigir investimento menor e ser direcionada para a base da pirâmide implica em uma valoração diferenciada quanto aos elementos chave de uma franquia, ou seja, a qualidade do suporte ao franqueado e a marca da franquia. Tal afirmação está calcada nos pressupostos da teoria da escassez de recursos e para entendê-la, convido à reflexão exposta a seguir.

No sistema de franchising, o franqueador é o responsável pelo desenvolvimento da marca e produtos, estabelecimento do know-how de operação e pela capacitação dos franqueados. A estes últimos, trata-se de um negócio conveniente, pois possibilita a aquisição de conhecimentos e práticas comerciais provindos pelo franqueador. A existência desse suporte por parte do franqueador faz com que o sistema de franquias apresente menores riscos de insucesso do que os negócios independentes. $\mathrm{O}$ franqueado, por sua vez, em troca desse suporte, compensa o franqueador através do pagamento de taxas de instalação da franquia, publicidade e royalties mensais (Combs, Michael, \& Castrogiovanni, 2004; Dant, Grunhage, \& Windsperger, 2011).

Contudo, é essencial mencionar que o modelo de operação do franchising aqui exposto, tal como ideal, muitas vezes entra em conflito com a realidade, em essencial se partir do pressuposto de que o modelo de franchising de um negócio inicia-se em razão da escassez de recursos da firma (Oxenfeldt \& Kelly, 1968). O sistema de franchising seria uma opção de expansão para as firmas, dada uma situação de escassez de recursos. Essa restrição de recursos pode ser caracterizada por indisponibilidades financeiras, de funcionários, gerencial e mesmo informacional sobre o conhecimento dos mercados e locais de operação (Mariz-Pérez \& García- Álvarez, 2009; Oxenfeldt \& Kelly, 1968; Shane, 1996a, 1996b). Em virtude dessas limitações, diversos recursos podem ser adquiridos e desenvolvidos mediante a adoção do sistema de franchising, especialmente por pequenas empresas (Carney \& Gedajlovic, 1991), pois esse modelo de negócios é capaz de propiciar um rápido crescimento sem que sejam necessários investimentos financeiros em sua totalidade do franqueador (Mariz-Pérez \& García- Álvarez, 2009; Oxenfeldt \& Kelly, 1968).

$\mathrm{O}$ cerne da questão em relação às microfranquias e a escassez de recursos encontra-se no modelo de negócio que os franqueadores têm de desenvolver para operar com restrições de recursos ainda maiores, considerando o menor investimento requerido dos franqueados. Os atributos essenciais do sistema de franchising, como o suporte ao franqueado e a marca da rede, apresentam entraves superiores às redes de microfranquias.

\section{Hipóteses}

A Figura 1 ilustra a proposição central anteriormente mencionada na ótica da escassez de recursos para as microfranquias, e abre espaço para a argumentação das hipóteses que serão apresentadas a seguir. 


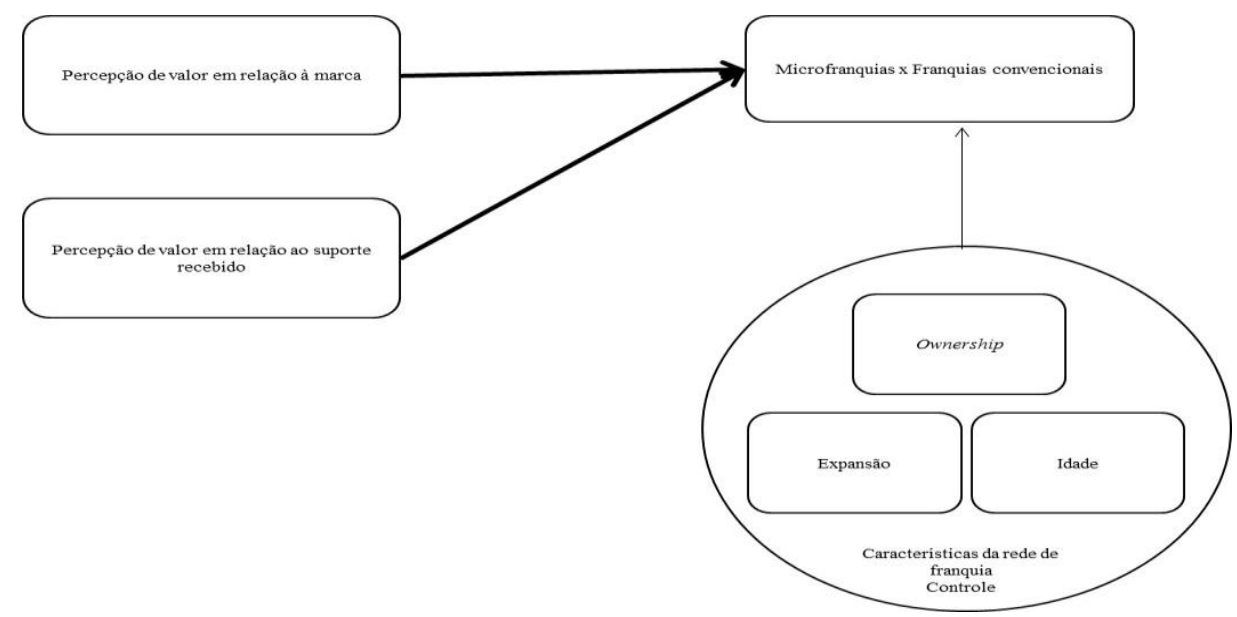

Figura 1. Framework de Sustentação à Pesquisa.

Fonte: Elaborado pelos autores.

\section{Percepção de valor do suporte pelo franqueado}

Zeithaml (1988) é um dos autores clássicos que, diante da extensa discussão sobre a definição de valor e percepção de valor, conseguiu estabelecer que "valor poder ser descrito em uma definição geral: Percepção de valor é uma estimação feita pelo consumidor em relação à utilidade do produto baseado nas percepções sobre o que é recebido e o que é oferecido" (p. 14, tradução livre).

O conceito de valor em uma relação entre franqueador e franqueado tem como base o balanço entre os pagamentos feitos pelos franqueados, nesse caso envolvendo o montante financeiro para a instalação e as taxas de manutenção em uma franquia, e, de outro lado, os benefícios gerados pelo franqueador, estando relacionado com o suporte e os atributos da marca oferecida nesta franquia (Grace \& Weaven, 2011; Michael, 1999).

Por sua vez, a percepção de valor proveniente do suporte ao franqueado deriva do valor epistêmico gerado pelo franqueador. $O$ franqueado possui um maior nível de satisfação com o franqueador devido ao ganho de habilidade e conhecimentos providos no suporte ao franqueado (Whittaker, Ledden, \& Kalafatis, 2007). Entretanto, mesmo que se trate de uma temática de relevância ao sistema de franchising, são poucos os estudos que aprofundam a percepção de valor dos serviços providos aos franqueados (Chiou, Hsieh, \& Yang, 2004; Grace \& Weaven, 2011; Harmon \& Griffiths, 2008; Huang \& Phau, 2009).

A percepção de valor dos serviços fornecidos pelo franqueador não é uma medida objetiva e estática, sendo influenciada fortemente pela subjetividade do franqueado, havendo variações constantes nessas percepções de valor, restando ao franqueador alinhar frequentemente o nível dos serviços ofertados e as taxas cobradas aos franqueados (Chiou et al., 2004; Gupta \& Zeithaml, 2006).

O suporte fornecido pelo franqueador aos seus franqueados é composto por serviços que irão moderar o relacionamento entre as partes, influenciando o nível de satisfação do franqueado com a rede à qual pertence. Esses serviços envolvem diversos tipos de suporte, como treinamentos e orientações operacionais. Os franqueados, por sua vez, são aqueles que determinarão, por meio de sua percepção, o valor nesta parceria, como beneficiados dos serviços dos franqueadores (Chiou et al., 2004; Falbe \& Welsh, 1998, Vargo \& Lusch, 2004a, 2004b).

Para Chiou, Hsieh e Yang (2004), as redes de franquias que possuem canais e comunicação bem desenvolvidos com os seus franqueados têm maiores condições de aumentar o nível de satisfação destes. Uma das maneiras de se desenvolver tal atributo se dá pelas consultorias de campo e pela formulação de manuais de operação, visando à sua efetividade, dadas as necessidades dos franqueados em suas operações cotidianas. 
Ademais, há registros de pesquisa em que constam variações nos serviços oferecidos aos franqueados, de acordo com o tamanho da rede de franquias. Grünhagen, DiPietro, Stassen e Frazer (2008) identificaram que as redes de franquias maiores fornecem um maior número de serviços de suporte aos seus franqueados.

Assim, os franqueados convencionais apresentam maior percepção de valor quanto à qualidade do suporte em relação aos microfranquedos por pertencerem às redes com maior poder de investimentos financeiros, esperando um melhor assessoramento do franqueador. Diante disso, pode ser suposto que:

H1: A percepção de valor dos microfranqueados é inferior à dos franqueados convencionais quanto à qualidade do suporte provido pelo franqueador.

\section{Percepção de valor da marca pelo franqueado}

Considera-se o valor de uma marca tanto pelo seu aspecto financeiro, como diante da perspectiva de valor percebido pelo consumidor, que é o aspecto abordado no desenvolvimento desta hipótese de pesquisa. Entretanto, a figura do stakeholder franqueado remete que este não deve ser tratado como um consumidor regular, mas sim como um empreendedor que busca no sistema de franchising o investimento de suas economias pessoais. Sendo a marca, por sua vez, um recurso valioso que o franqueado considera na aquisição de uma franquia (Aaker, 1991, 1996; Ghantous \& Jaolis, 2013; Kim, Kim, \& An, 2003; Pride \& Ferrell, 2003). Do mesmo modo, não se pode menosprezar o valor da marca para uma microfranquia.

Cabe destacar o comportamento dos empreendedores que buscam franquias; este é atraído por um pacote de benefícios fornecidos pelo franqueador, que contemplam o suporte operacional e a utilização de marcas desenvolvidas e gerenciadas pela rede. Em contrapartida, o franqueado assume o pagamento de taxas, visando o provimento desta parceria com o franqueador. A diferença entre os benefícios gerados e as taxas pagas pelos franqueados resulta no valor criado pelo franqueador (Combs et al., 2004; Grace \& Weaven, 2011).

Em uma definição, aplicada particularmente ao franchising, Ghantous e Jaolis (2013) cunharam o termo franchisee-based brand equity definindo como "o valor adicionado pela marca diante do pacote de benefícios oferecido ao franqueado" (p. 114, tradução livre). Além desse foco no franqueado quando se fala de marca em franquias, considera-se também a percepção do consumidor final. Dessa forma, o conceito de percepção de qualidade refere-se a atributos subjetivos qualificados pelo franqueado (consumidor), havendo autores que consideram a percepção de qualidade como um constructo influenciável pela brand equity (Erenkol \& Duygun, 2010; Zeithaml, 1988).

Assim, a força de uma marca é construída pela percepção dos consumidores, baseada principalmente em suas experiências anteriores diante do desempenho dos produtos e serviços e sua comparação com os produtos e serviços providos pelos concorrentes. Essa percepção de valor da força da marca influenciará a escolha futura por bens desta mesma marca. A marca torna-se cada vez mais importante para o franqueado à medida que os consumidores retornam a realizar transações comerciais em suas franquias. Adicionalmente, há estudos que demonstram que a força de uma marca em franquia é um elemento determinante para a atração e a retenção de franqueados em uma rede (Ghantous \& Jaolis, 2013; Nyadzayo, Matanda, \& Ewing, 2011).

A percepção dos consumidores frente às marcas tem como um dos atributos a percepção de risco referente à escolha por uma rede de franquias, esta que afeta a credibilidade do franqueador perante os seus franqueados, sendo um influenciador na decisão de aquisição e satisfação dos franqueados. Além disso, a percepção de risco está relacionada à confiança e à cooperação entre os stakeholders (Aqueveque, 2006; DelVecchio \& Smith, 2005; Ghantous \& Jaolis, 2013; Morgan \& Hunt, 1994; Rego, Billet, \& Morgan, 2009). 
Complementando esta argumentação, em um estudo recente, Grace e Weaven (2011) testam as dimensões de valor que influenciam as percepções de risco e satisfação dos franqueados. Neste estudo, evidenciou-se que o status da marca de uma rede de franquias influencia no julgamento dos franqueados quanto ao risco de investimento. McAlister, Srinivasan e Kim (2007); Singh, Faircloth e Nejadmalayeri (2005) são autores que constatam resultados similares, ao identificarem no comportamento de investidores do mercado acionário a predileção por empresas com marcas de maior reconhecimento público como sinalizador de menor risco de investimento.

Diante dessa discussão envolvendo percepção de valor quanto à qualidade de uma marca, é esperado que os franqueados convencionais apresentem uma maior percepção de valor face aos microfranqueados. Isso porque as franquias convencionais têm maior estrutura e recursos para trabalhar uma marca e oferecer mais valor aos seus consumidores (sejam eles finais ou franqueados). Ademais, outro elemento que faz crer nesta linha de raciocínio é o fato desses franqueados terem adquirido marcas com maior poder de atração de consumidores, além de apresentarem franqueadores com maior credibilidade no mercado de franquias, que remeterá a um menor risco de investimento. Diante disto, pode ser afirmado que:

H2: A percepção de valor dos microfranqueados é inferior à dos franqueados convencionais quanto à qualidade da marca.

\section{Metodologia}

\section{Descrição do método e procedimentos}

Os dados utilizados nesta pesquisa são oriundos do anuário Guia de Franquias, publicação da revista Pequenas Empresas e Grandes Negócios (PEGN), auditado pelo Serasa Experian, e do Guia Oficial de Franquias, publicação da Associação Brasileira de Franchising. As edições utilizadas compreendem os anos de 2007 a 2012.

Devido à existência de associações de franquias neste segmento, é possível encontrar diversos estudos internacionais vinculados em importantes journals que se utilizaram de dados provenientes de anuários de franquias. A principal vantagem ao se utilizar esses anuários reside na disponibilidade de dados sobre muitas redes de franquias. Essas produções científicas datam do início dos anos 90 até os presentes anos (Castrogiovanni \& Justis, 2002; Combs \& Castrogiovanni, 1994; Dant, Perrigot, \& Cliquet, 2008; Elango, 2007; Mariz-Pérez \& García-Álvarez, 2009). As variáveis dependentes relacionadas às hipóteses desse artigo são constituídas pelo agrupamento dos atributos apresentados na Tabela 1.

Tabela 1

Constituição das Variáveis

\begin{tabular}{clll}
\hline Hipótese & Variável & Constituição da variável & Atribuição score \\
\hline H1 & $\begin{array}{l}\text { Percepção de valor do suporte } \\
\text { pelo franqueado }\end{array}$ & $\begin{array}{l}\text { - Treinamento } \\
\text { • Consultoria de campo } \\
\text { • Manual de operações }\end{array}$ & $\begin{array}{l}\text { Nota média considerando os três } \\
\text { aspectos relacionados na coluna ao } \\
\text { lado. Expresso como um índice } \\
\text { variável entre 0 e 10 pontos. }\end{array}$ \\
H2 & $\begin{array}{l}\text { Percepção de valor da marca } \\
\text { pelo franqueado }\end{array}$ & $\begin{array}{l}\text { - Força da marca } \\
\text { - Solidez e transparência }\end{array}$ & $\begin{array}{l}\text { Nota média considerando os dois } \\
\text { aspectos relacionados na coluna ao } \\
\text { lado. Expresso como um índice } \\
\text { variável entre 0 e 10 pontos. }\end{array}$ \\
\hline
\end{tabular}

Nota. Fonte: elaborado pelos autores. 
A variável independente dos modelos é o fato da franquia ser uma microfranquia (investimento menor que R\$50 mil) ou franquia convencional. Tal variável constitui uma dummy em que 1 é a microfranquia e 0 , a franquia convencional. Como o valor $\mathrm{R} \$ 50$ mil é definido pela $\mathrm{ABF}$ e pode mascarar variações de investimento para cima ou para baixo, na análise do modelo de regressão será feita uma análise de sensitividade com diferentes modelos de regressão, tal qual a simulação da dummy de microfranquias para investimentos inferiores e superiores que R $\$ 50$ mil. Assim, serão apresentados na análise de sensibilidade cinco modelos em que a dummy de micro franquia terá os cortes de investimento menores que R $\$ 40$ mil (modelo A); investimento menor que R\$ 60 mil (modelo B); investimento menor que R $\$ 70$ mil (modelo C) e, por fim, para testar um extremo e verificar se existe uma variância, será testada a dummy de microfranquias com investimento menor que $\mathrm{R} \$ 100$ mil (modelo D).

Além da variável independente, foram usadas três variáveis de controle: ownership (relação entre unidades próprias e franqueadas), expansão da franquia e idade da franquia, tal como justificado na seção seguinte do presente estudo. A variável ownership mede o número de unidades próprias do franqueador em relação ao número de unidades franqueadas. Por sua vez, a variável idade mede a idade da franquia contando os anos desde a sua adoção pelo sistema de franchising. Por fim, a expansão da franquia é medida pelo número de unidades abertas em cada ano.

\section{Aspectos de controle}

No presente estudo, foram usados três aspectos de controle: ownership (relação entre unidades próprias e franqueadas), a idade da franquia e a expansão da franquia. Isso porque se entende que esses três aspectos precisavam ser controlados, já que o maior ou menor grau deles poderia influenciar na percepção de valor da qualidade do suporte e da marca das microfranquias. Logo, se esses fatores não são medidos para verificar sua interveniência, os resultados podem ser enviesados, pois a explicação para a percepção de valor não seria somente decorrente da modalidade de negócio ser microfranquia ou franquia convencional. Desse modo, abaixo são tecidas as considerações sobre os três aspectos em questão.

\section{Ownership}

O ownership de uma franquia pode ser conceituado como a pulverização de uma rede de franquias entre lojas próprias (o dono é o próprio franqueador) e lojas franqueadas (Oxenfeldt \& Kelly, 1968). Os estudos apontam para duas direções sobre qual fenômeno estudar nessa relação: (a) o melhor equilíbrio entre lojas franqueadas e próprias considerando os custos de transação e controle (Combs \& Catrogiovanni, 1994); ou (b) como encontrar um melhor balanço entre lojas próprias e franqueadas, dados os danos morais causados pelo franqueado em relação à marca da rede (Perryman \& Combs, 2012).

Essa discussão emerge do fato de existirem dificuldades de monitoramento nas relações franqueador-franqueado que não devem ser menosprezadas, dado que os incentivos de monitorar e supervisionar os empregados são menores quando existe maior ownership (Krueger, 1991). De fato, o desempenho do franqueado está relacionado com o suporte recebido do franqueador. Com isso, caso um franqueado consiga se afiliar a uma rede de franquias em que o franqueador e os franqueados tenham experiência para poder ajudá-lo, a chance de o negócio falhar é menor (Nijmeijer, Fabbricotti, \& Huijsman, 2014). Logo, o ownership do franqueado deve ser considerado como controle, pois o fato deste ter uma percepção menor do suporte e da marca pode ser devido ao baixo ownership das microfranquias e não necessariamente devido à modalidade do negócio. Desse modo, para controlar esse aspecto, será usado no modelo a variável de controle ownership.

\section{Idade da rede de franquia}

A idade de uma rede de franquias serve como um dos indicadores para se medir a posse de recursos acumulados pelo franqueador. Essa posse de recursos está relacionada à maior capacidade de suporte fornecido aos franqueados e ao desenvolvimento da sua marca. Com o passar dos anos, a rede 
de franquias tem a maior capacidade de desenvolver competência referente aos atributos constituintes do sistema de franchising. Nessa lógica, as redes mais antigas teriam maior capacidade de fornecer suporte aos seus franqueados, e possuir marcas de maior prestígio (Bradach, 1997; Castrogiovanni, Combs, \& Justis, 2006; McIntyre \& Huszagh, 1995; Oxenfeldt \& Kelly, 1968; Shane, 1996a, 1996b). Como o fenômeno das microfranquias é recente, torna-se importante a variável idade como controle, pois os resultados de qualidade do suporte e da marca inferior da microfranquia podem ser resultantes da idade inferior dessas redes perante as convencionais.

\section{Expansão da franquia}

Por fim, o terceiro aspecto a ser controlado é a expansão da franquia. As redes que apresentam um rápido processo de crescimento possuem um maior desafio em capacitar os seus funcionários e franqueados e desenvolver concomitantemente os atributos do sistema de franchising (Shane, 1996a). Ou seja, o crescimento moderado favorece o desenvolvimento da qualidade do suporte e da marca. Por sua vez, o crescimento rápido corre o risco de saturar os mercados e canibalizar as vendas das franquias existentes (Kaufmann \& Rangan, 1990; Shane, 1996a). Logo, é importante monitorar no modelo exposto a taxa de expansão das microfranquias, pois a menor qualidade do suporte e da marca pode ser decorrente não da modalidade microfranquia, mas da taxa de expansão acelerada.

\section{Técnicas estatísticas}

Neste estudo, o modelo da regressão OLS foi estimado para avaliar se e em que medida a variável independente (microfranquia) está associada à variável dependente 1 (percepção de valor do suporte - variando de 0 e 10) e à variável dependente 2 (percepção de valor da marca - variando de 0 e 10). Nos modelos, testou-se a significância a $p<0,05$ dos coeficientes da variável independente e de controle, e foi observado o R quadrado (R2) ajustado para verificar a capacidade de explicar a variação observada (Hair, Black, Babin, Anderson, \& Tatham, 2009).

\section{Estudos de caso}

Adicionalmente, foram realizados três estudos de casos envolvendo microfranqueados. Para Creswell (2003), os fenômenos das ciências humanas e sociais são observados pelos cientistas de forma complexa, de maneira que cada vez menos uma abordagem meramente quantitativa ou meramente qualitativa é capaz de explicar os fatos. Por isso, o autor defende o uso de métodos múltiplos (mixed methods), capazes de abranger múltiplas fases da pesquisa, cada uma com sua abordagem epistemológica. Diante disso, o presente estudo se sustenta numa análise quantitativa para comparação entre franquias convencionais e microfranquias, além do uso de abordagem qualitativa perante os microfranqueados. Essa estratégia de pesquisa foi adotada com o intuito de que os resultados pudessem ser confrontados, e os dados quantitativos pudessem ser confirmados de maneira que o entendimento sobre como e por quê das variáveis abordadas pudessem ser melhor compreendidos.

Os microfranqueados em operação na Grande São Paulo foram contatados aleatoriamente a partir de uma listagem divulgada no site da ABF em fevereiro de 2014. Dos cerca de 130 e-mails enviados convidando para participarem da pesquisa, sete microfranqueados se predispuseram a participar. Os critérios para escolha dos três microfranqueados selecionados para este estudo se basearam: (a) no tempo de fundação da rede; (b) no tempo de adoção da rede ao sistema de franchising; (c) no tempo de experiência do empreendedor como microfranqueado; e, (d) no número de unidades franqueadas pela rede. Deu-se o peso igual para cada critério, selecionando-se os microfranqueados que apresentaram maiores pontuações. Essas questões são relevantes para se analisar redes que possuam maior maturidade nos mecanismos de franchising (Elango, 2007; Shane, 1996b). 
As entrevistas foram previamente agendadas por e-mail e telefone, tendo ocorrido presencialmente no estabelecimento comercial destes microfranqueados no mês de fevereiro de 2014. Os microfranqueados selecionados fazem parte dos respectivos segmentos: Educação e Treinamento e Saúde e Bem Estar.

Os questionários elaborados para as entrevistas tiveram como referências questões sobre: (a) os antecedentes pessoais do empreendedor (Carvalho \& González, 2006; Farmer, Yao, \& Kung-McIntyre, 2011); (b) a avaliação do suporte ao franqueado (Monroy \& Alzola, 2005); e (c) avaliação da marca (Nyadzayo et al., 2011; Pitt, Napoli, \& Van Der Merwe, 2003).

\section{Resultados}

A base de dados que deu origem ao estudo é composta por 3233 observações de campo representando 1090 franquias, com observações de seis anos, de 2007 até 2012. Contudo, para a realização da presente análise, consideraram-se apenas as franquias que não apresentavam dados faltantes em nenhum dos anos em relação às variáveis usadas. Os dados faltantes podem ser gerados devido às razões apontadas na sequência.

No Guia Oficial de Franquias, publicado pela Associação Brasileira de Franquias (ABF), o condicionante para estar neste anuário reside no fato da rede ser associada à $\mathrm{ABF}$. Os dados faltantes, nesse caso, podem ocorrer devido ao descredenciamento ou à filiação de determinada rede à $\mathrm{ABF}$ no decorrer dos anos analisados neste estudo. O quadro de variação no número de associados é potencializado devido às altas taxas de crescimento do número de redes de franquias, superiores a $15 \%$ média/anual no período analisado (ABF, 2014). Mesmo que não seja obrigatório se associar à $A B F$, deduzimos que um crescimento expressivo do setor tende a refletir um aumento no número de associados da entidade representativa das redes de franquias.

Por sua vez, o Guia de Franquias, editado pela revista Pequenas Empresas \& Grandes Negócios e pela Serasa (PEGN/Serasa) apresenta dois grupos de franquias. O primeiro é composto por 500 redes de franquias escolhidas aleatoriamente pelo PEGN/Serasa. O segundo grupo é composto pelas redes com melhores scores diante dos seguintes critérios de desempenho adotados: crescimento do faturamento, crescimento do número de lojas das redes, treinamento, consultoria interna, manual de operações, suporte ao franqueado, força da marca, solidez e transparência da rede, variando de 300 a 400 redes anualmente. Neste segundo grupo, as redes de franquias possuem um maior número de indicadores, inclusive as variáveis dependentes utilizadas no cruzamento deste artigo.

Assim, as redes de franquia que não apresentaram desempenho adequado que as qualificassem para serem incluídas no segundo grupo, restrito às melhores redes, segundo o Serasa, geraram dados faltantes. Com isso, entendemos que, ao fazermos a opção de exclusão dos dados faltantes, conseguimos selecionar as redes com melhores scores no período analisado. Dado esse ajuste, o número final de casos válidos é de 1090 franquias no mesmo período anteriormente relatado.

Nesta amostra, 11,3\% (174) das franquias são microfranquias. É importante ressaltar que, de ano para ano, varia o número de microfranquias, já que algumas passam para a categoria de franquias convencionais e outras deixam de existir. Assim, em 2007, a amostra tem 16\% (34) de microfranquias perante $14 \%$ (25) em 2008, $10 \%$ (24) em 2009, $9 \%$ (25) em 2010, 10\% (33) em 2011 e $11 \%$ (33) em 2012.

A Tabela 2 mostra a correlação entre as variáveis independentes e de controle do modelo e o teste de multicolinearidade entre elas. A única correlação significativa entre micro franquias e ownership é uma correlação fraca, os demais dados mostram a ausência de uma correlação forte que possa causar a multicolinearidade, o que é comprovado pelos valores de VIF próximos a 1 e abaixo de 5 (Hair et al., 2009). 
Tabela 2

Correlações

\begin{tabular}{ccccccc}
\cline { 3 - 7 } & & $\mathbf{1}$ & $\mathbf{2}$ & $\mathbf{3}$ & $\mathbf{4}$ & VIF \\
\hline 1 & Ownership & 1 & & & & 1.001 \\
2 & Idade & -0.014 & 1 & & & 1.001 \\
3 & Expansão & -0.009 & 0.008 & 1 & & 1.000 \\
4 & Micro & $0.221^{* *}$ & 0.013 & -0.03 & 1 & 1.001 \\
\hline
\end{tabular}

Nota. ${ }^{*} \mathrm{p}<0.01 ; * \mathrm{p}<0.05$. Fonte: elaborado pelos autores.

A Tabela 3 mostra o teste de regressão OLS que permite testar as hipóteses levantadas, assim como averiguar a influência dos aspectos de controle. Nos modelos 1a (suporte) e 1b (marca), é testado para todos os anos apenas o impacto das variáveis de controle. Os modelos $2 \mathrm{a}$ (suporte) e $2 \mathrm{~b}$ (marca) testam, para todos os ano, o impacto das variáveis de controle e das variáveis independentes no modelo para todos os anos. Os demais modelos, de $3 \mathrm{a}$ a $8 \mathrm{a}$ (suporte) e de $3 \mathrm{~b}$ a $8 \mathrm{~b}$ (marca), testam o impacto das variáveis para os anos especificados, partindo de 2007 até 2012.

Tabela 3

Modelos de Regressão OLS

\begin{tabular}{|c|c|c|c|c|c|c|c|c|}
\hline & $\begin{array}{c}\text { Mod 1a } \\
\text { 2007-2012 }\end{array}$ & $\begin{array}{c}\text { Mod 2a } \\
\text { 2007-2012 }\end{array}$ & $\begin{array}{c}\text { Mod 3a } \\
2007\end{array}$ & $\begin{array}{c}\text { Mod 4a } \\
2008\end{array}$ & $\begin{array}{c}\text { Mod 5a } \\
2009\end{array}$ & $\begin{array}{c}\text { Mod 6a } \\
2010\end{array}$ & $\begin{array}{c}\text { Mod 7a } \\
2011\end{array}$ & $\begin{array}{c}\text { Mod 8a } \\
2012\end{array}$ \\
\hline Constante & 6,642 & 6,646 & 6,351 & 6,988 & 6,249 & 6,512 & 6,211 & 6,578 \\
\hline Ownership & ,047 & ,047 & ,065 & ,082 &, 112 & ,168 & ,083 & ,007 \\
\hline Idade & $0.001^{*}$ & $0.001^{*}$ & $0.024^{*}$ & ,001 & $0.029 *$ & $.001 *$ & $0.028 *$ & ,012 \\
\hline Expansão &,- 001 &,- 001 &, 000 &,- 005 &,- 004 & ,001 &,- 001 &,- 001 \\
\hline Micro & &,- 043 & ,342 & ,296 &, 104 &.-.383 & ,228 &,- 381 \\
\hline $\mathrm{F}$ & $3.165^{*}$ & $2.404^{*}$ & 1,737 &, 513 & 1,689 & 3691 & 1,943 & 1,102 \\
\hline \multirow[t]{2}{*}{ R2 ajustado } & 0,01 & 0,01 &, 031 & ,012 &, 028 & ,032 &, 028 &, 015 \\
\hline & $\begin{array}{c}\text { Mod 1b } \\
\text { 2007-2012 }\end{array}$ & $\begin{array}{c}\text { Mod 2b } \\
\text { 2007-2012 }\end{array}$ & $\begin{array}{c}\text { Mod 3b } \\
2007\end{array}$ & $\begin{array}{c}\text { Mod 4b } \\
2008\end{array}$ & $\begin{array}{c}\text { Mod 5b } \\
2009\end{array}$ & $\begin{array}{c}\text { Mod 6b } \\
2010\end{array}$ & $\begin{array}{c}\text { Mod 7b } \\
2011\end{array}$ & $\begin{array}{c}\text { Mod 8b } \\
2012\end{array}$ \\
\hline Constante & 5,969 & 6,096 & 7,408 & 4,929 & 4,922 & 5,691 & 4,855 & 4,666 \\
\hline Ownership &,- 044 &,- 050 &,- 050 & ,049 &,- 030 &,- 136 &,- 151 &,- 005 \\
\hline Idade & ,000 & ,000 &,- 002 & $0.106^{* *}$ & $0.108 * *$ &,- 001 & $0.097 * *$ & $0.067 * *$ \\
\hline Expansão & $0.003^{*}$ & $0.003^{* *}$ & $0,003^{*}$ & $0.010^{*}$ & $0.006^{*}$ & $0.008^{* *}$ & $0.004 * *$ & $0.001^{*}$ \\
\hline Micro & & $-1.172 * *$ &.$-1.412 * *$ &.$-0.904 * *$ &.$-1.481 * *$ &.$-1.514 * *$ &.$-1.250 * *$ & $-0.874 * *$ \\
\hline $\mathrm{F}$ & 5,431 & $23.848^{*}$ & $5.156^{* *}$ & $29.878 * *$ & $34.805^{* *}$ & $11.859 * *$ & $38.800 * *$ & $32.778 * *$ \\
\hline R2 ajustado & 0,01 & 0,06 &, 071 & ,396 & ,358 & ,138 & ,359 & ,307 \\
\hline
\end{tabular}

Nota. $* \mathrm{p}<0,05 ; * * \mathrm{p}<0,01$. Fonte: elaborado pelos autores.

Referente à percepção de valor quanto à qualidade do suporte, os resultados observados nos modelos referentes a cada ano (modelos $3 \mathrm{a}$ a $8 \mathrm{a}$ ) não apresentam um ajuste adequado ( $\mathrm{F}$ não significante). Por sua vez, no modelo geral (modelo 2a), apesar do F significante, os resultados mostram a inexistência da associação $(\mathrm{p}<0.05)$ entre uma menor percepção de valor da qualidade do 
suporte nas microfranquias quando comparada com as franquias convencionais. Dessa forma, não pode ser suportada a $\mathrm{H} 1$ : A percepção de valor dos microfranqueados é inferior à dos franqueados convencionais quanto à qualidade do suporte provido pelo franqueador. Por outro lado, verifica-se uma associação entre idade e qualidade do suporte (modelos 1a e 2a), ou seja, o tempo de existência da rede tende a ter uma associação positiva com uma percepção melhor da qualidade do suporte, porém, apesar de ser significante, seu poder de explicação é mínimo.

Por outro lado, tanto no modelo geral (2b) como nos modelos específicos para cada ano (3a e $3 b$ ), os resultados mostram que existe uma associação entre o fato de ser um microfranqueado e a menor percepção de valor quanto à qualidade da marca. Dessa maneira, é suportada a H2: A percepção de valor dos microfranqueados é inferior à dos franqueados convencionais quanto à qualidade da marca. Esse resultado mostra que, apesar de não existir diferença quanto à qualidade do suporte, as microfranquias têm uma percepção de valor concedida pelos franqueados inferior no que tange a qualidade da marca. Portanto, se existe algo que deve ser discutido quanto às particularidades do modelo de microfranquias é a questão mercadológica inerente à gestão da marca da rede. A suposição aqui defendida é que a percepção da qualidade da marca dos microfranqueados é inferior em virtude de não ter a mesma força de marca, solidez e transparência de marca que as franquias convencionais. Isso mostra que o desafio das redes de microfranquias reside na gestão da qualidade da marca.

Ainda em relação à qualidade da marca, percebe-se a associação positiva entre a expansão da rede e a percepção da qualidade da marca. Esse resultado mostra que a expansão da rede está associada à maior qualidade da marca. Isso levanta a hipótese de que, se uma microfranquia tem uma expansão muito forte, a percepção negativa em relação à qualidade da marca pode ser atenuada e até mesmo anulada. Todavia, os resultados dos testes de verificação apresentados na Tabela 4 (modelo I) mostram que essa hipótese não é suportada, ou seja, para as franquias convencionais a expansão da rede está associada a uma melhor percepção da marca, porém isso não é verdade para as microfranquias. Observa-se, também em alguns modelos específicos de cada ano (2008, 2009, 2011, 2012), que o tempo de existência está associado a uma melhor percepção do valor da marca. Contudo, os testes de interação (modelo II, III, IV, V) na Tabela 4 mostram que inexiste a associação entre maior tempo de experiência e uma melhor avaliação da qualidade da marca, de tal forma que o tempo de experiência apenas incrementa a percepção de maior valor da marca para as franquias convencionais.

Tabela 4

\section{Testes de Verificação}

\begin{tabular}{lccccc}
\hline \multicolumn{1}{c}{ Marca } & Modelo I & $\begin{array}{c}\text { Modelo II } \\
(\mathbf{2 0 0 8})\end{array}$ & $\begin{array}{c}\text { Modelo III } \\
(\mathbf{2 0 0 9})\end{array}$ & $\begin{array}{c}\text { Modelo IV } \\
(\mathbf{2 0 1 1})\end{array}$ & $\begin{array}{c}\text { Modelo V } \\
(\mathbf{2 0 1 2})\end{array}$ \\
\hline Constante & 6.099 & 4831 & 4916 & 4877 & 4685 \\
Ownership & -.049 & .053 & -.024 & -.151 & -.004 \\
Expansão & $.003^{* *}$ & .011 & .006 & .005 & .001 \\
Idade & .001 & $.113^{* *}$ & $.110^{* *}$ & $.096^{* *}$ & $.066^{* *}$ \\
Micro & $-1.210^{* *}$ & $-.959^{* *}$ & $-1.637^{* *}$ & $-1.139^{* *}$ & $-.902^{* *}$ \\
Micro x Expansão & .002 & .007 & .008 & .008 & .007 \\
Micro x Idade & $-\mathrm{X}-$ & -.040 & -.013 & .031 & .016 \\
F & $19146^{* *}$ & $20242^{* *}$ & $23110^{* *}$ & $25797^{* *}$ & $22677^{* *}$ \\
R2 ajustado & .060 & .396 & .354 & .355 & .312 \\
\hline
\end{tabular}

Nota. ${ }^{*} \mathrm{p}<0,05 ; * * \mathrm{p}<0,01$. Fonte: elaborado pelos autores.

Por fim, a Tabela 5 mostra um teste de sensibilidade quanto à faixa de corte para determinar as microfranquias, tal como explicado na metodologia. Os resultados se mostram consistentes para as 
diferentes taxas de corte, ou seja, as considerações tecidas anteriormente para a divisão de $\mathrm{R} \$ 50$ mil valem para as variações especificadas no modelo abaixo.

Tabela 5

Teste de Sensibilidade

\begin{tabular}{lccccccccc}
\hline Suporte & Mod A & Mod B & Mod C & Mod D & Marca & Mod A & Mod B & Mod C & Mod D \\
\hline Constante & 6.504 & 6.632 & 6.587 & 6.656 & Constante & 4.955 & 5.145 & 5.306 & 5.403 \\
Ownership & .045 & .047 & .047 & .046 & Ownership & -.047 & -.052 &.-053 & -.056 \\
Expansão & -.001 & -.001 & -.001 & -.001 & Expansão & $.003^{*}$ & $.003^{*}$ & $.003^{*}$ & $.003^{*}$ \\
Idade & $001^{*}$ & $001^{*}$ & $001^{*}$ & $001^{*}$ & Idade & .000 & .000 & .000 & .000 \\
Micro & .150 & .011 & .067 & .101 & Micro & $-1.100^{* *}$ & $-.965^{* *}$ & $-.808^{* *}$ & $-.742^{* *}$ \\
F & $2.664^{*}$ & $2.375^{*}$ & $2.489^{*}$ & $2.692^{*}$ & $\mathrm{~F}$ & $17239^{* *}$ & $21716^{* *}$ & $18363^{* *}$ & $18717^{* *}$ \\
R2 ajustado & .01 & .01 & .01 & .01 & R2 ajustado & .042 & .053 & .045 & .049 \\
\hline
\end{tabular}

Nota. ${ }^{*} \mathrm{p}<0,05 ; * * \mathrm{p}<0,01$. Fonte: elaborado pelos autores.

\section{Estudo de Casos: Microfranquias}

\section{Microfranquia A: educação e treinamento}

A microfranquia A trata-se de uma rede de franquias dedicada ao reforço escolar, com aulas de tutoria voltadas a: ensino fundamental, preparatório para o Enem, vestibulares, português para estrangeiros e informática para a terceira idade.

Essa rede de franquias é uma das pioneiras no segmento de microfranquias brasileiras, tendo sido fundada em 2007 e operando através do sistema de franchising desde 2008. Atualmente, a rede possui 76 unidades franqueadas e nenhuma unidade própria. $\mathrm{O}$ capital necessário para a instalação de uma unidade é de $\mathrm{R} \$ 30.000,00$, e as taxas de royalties são fixas, variando de acordo com o porte da cidade, entre 1 e 3 salários mínimos.

\section{Microfranquia B: educação e treinamento}

A rede de microfranquias $\mathbf{B}$ faz parte de um dos maiores grupos de franquias brasileiras no segmento de educação. Os produtos oferecidos por essa microfranquia concentram-se em cursos de português, matemática, inglês e reforço escolar. Essa rede foi fundada em 2010, tendo início as operações por franchising em 2011. Atualmente, a rede possui 137 unidades e nenhuma unidade própria. O investimento inicial requerido varia entre $\mathrm{R} \$ 13$ e $\mathrm{R} \$ 58$ mil. As taxas de royalties estão condicionadas à compra do material fornecido pelo franqueador e, no caso, das aulas de reforço escolar.

\section{Microfranquia C: saúde e bem estar}

A microfranquia $\mathbf{C}$ é uma rede do setor de saúde e bem-estar. Trata-se de uma rede especializada em disponibilizar cuidadores de pessoas no método home care, oferecendo, assim, suporte emocional e físico para seus clientes. Seu foco principal de atuação está na oferta de cuidadores para idosos. 
A empresa foi fundada em 2008 e aderiu ao sistema de franchising em 2009, possui cerca 89 unidades franqueadas e nenhuma unidade própria. O capital necessário para se abrir uma franquia dessa rede é de $\mathrm{R} \$ 20$ a $\mathrm{R} \$ 40$ mil.

A Tabela 6 apresenta as características relativas aos antecedentes pessoais dos microfranqueados analisados, a avaliação dos franqueados relativas ao suporte ao franqueado e à marca da rede.

Tabela 6

\section{Análise dos Microfranqueados}

\begin{tabular}{|c|c|c|c|}
\hline Atributo analisado & Microfranqueado A & Microfranqueado B & Microfranqueado C \\
\hline Segmento de atuação & Educação e Treinamento & Educação e Treinamento & Saúde e Bem Estar \\
\hline $\begin{array}{l}\text { Tempo de adoção do sistema de } \\
\text { franchising pela empresa }\end{array}$ & 6 anos & 4 anos & 6 anos \\
\hline $\begin{array}{l}\text { Tempo de associação do } \\
\text { microfranqueado }\end{array}$ & 5 anos & 3 anos & 3,5 anos \\
\hline $\begin{array}{l}\text { Experiência prévia do } \\
\text { microfranqueado }\end{array}$ & $\begin{array}{l}\text { Coordenadora } \\
\text { pedagógica e proprietária } \\
\text { de um PetShop }\end{array}$ & $\begin{array}{l}\text { Proprietária de uma } \\
\text { pequena indústria de } \\
\text { guardanapos e ex- } \\
\text { franqueada Kumon }\end{array}$ & Assistente Social \\
\hline Suporte: treinamento & $\begin{array}{l}\text { Deficitário, concentrado } \\
\text { no atendimento ao } \\
\text { cliente, demais } \\
\text { treinamentos são falhos } \\
\text { ou ausentes. }\end{array}$ & $\begin{array}{l}\text { Deficitário, concentrado } \\
\text { no atendimento ao } \\
\text { cliente com o agravante } \\
\text { de não ser moldado para } \\
\text { o negócio em questão, } \\
\text { demais treinamentos são } \\
\text { falhos ou ausentes. }\end{array}$ & $\begin{array}{l}\text { Deficitário, apenas } \\
\text { treinamentos } \\
\text { operacionais. }\end{array}$ \\
\hline Suporte: consultoria de campo & $\begin{array}{l}\text { Deficitária, ocorre } \\
\text { somente via Skype. }\end{array}$ & $\begin{array}{l}\text { Deficitária, ocorre por } e \text { - } \\
\text { mail. }\end{array}$ & $\begin{array}{l}\text { Deficitária, ocorre por } e \text { - } \\
\text { mail e Skype. }\end{array}$ \\
\hline Suporte: manuais de operações & $\begin{array}{l}\text { Formalizado, não trata } \\
\text { de especificidades. }\end{array}$ & $\begin{array}{l}\text { Formalizado, não trata } \\
\text { de especificidades. }\end{array}$ & $\begin{array}{l}\text { Simplificado, mas com } \\
\text { algumas atualizações }\end{array}$ \\
\hline Marca: marca da rede & $\begin{array}{l}\text { Desconhecida e pouco } \\
\text { desenvolvida }\end{array}$ & $\begin{array}{l}\text { Desconhecida, atrelada a } \\
\text { uma grande holding de } \\
\text { franquias, entretanto sem } \\
\text { impacto nos } \\
\text { consumidores. }\end{array}$ & $\begin{array}{l}\text { Desconhecida e pouco } \\
\text { desenvolvida }\end{array}$ \\
\hline Marca: solidez & $\begin{array}{l}\text { Atributo não } \\
\text { desenvolvido }\end{array}$ & $\begin{array}{l}\text { Atributo não } \\
\text { desenvolvido }\end{array}$ & $\begin{array}{l}\text { Atributo não } \\
\text { desenvolvido }\end{array}$ \\
\hline $\begin{array}{l}\text { Marca: transparência e } \\
\text { oportunismo }\end{array}$ & $\begin{array}{l}\text { Falta de transparência } \\
\text { da marca e atitudes } \\
\text { oportunistas do } \\
\text { franqueador }\end{array}$ & $\begin{array}{l}\text { Falta de transparência da } \\
\text { marca e atitudes } \\
\text { oportunistas do } \\
\text { franqueador }\end{array}$ & $\begin{array}{l}\text { Falta de transparência da } \\
\text { marca e atitudes } \\
\text { oportunistas do } \\
\text { franqueador }\end{array}$ \\
\hline
\end{tabular}

Nota. Fonte: Adaptado de Carvalho, P., \& González, L. (2006). Modelo explicativo sobre a intenção empreendedora. Comportamento Organizacional e Gestão, 12(1), 43-60; Farmer, S., Yao, X., \& Kung-Mcintyre, K. (2011). The behavioral impact of entrepreneur identity aspiration and prior entrepreneurial experience. Entrepreneurship Theory and Practice, 35(2), 245-273. doi: 10.1111/j.1540-6520.2009.00358.x; Monroy, M. F., \& Alzola, L. M. (2005). An analyses of quality management in franchise systems. European Journal of Marketing, 39(5/6), 585-605. doi: 10.1108/03090560510590728; Pitt, L., Napoli, J., \& Van Der Merwe, R. (2003). Managing the franchised brand: The franchisee's perspective. Journal of Brand Management, 10(6), 411-420; Nyadzayo, M. W., Matanda, M. J., \& Ewing, M. T. (2011). Brand relationship and brand equity in franchising. Industrial Marketing Management, 40(7), 1103-1115. doi: 10.1016/j.indmarman.2011.09.004. 


\section{Discussão dos Resultados}

A compreensão entre a articulação e os resultados das hipóteses 1 e 2 passam pelo entendimento do conceito de percepção de valor. Como mencionado em vários trechos dessas hipóteses, a percepção de valor envolve julgamentos subjetivos na mente do avaliado, no caso, o franqueado. As hipóteses foram desenvolvidas acreditando que tanto a qualidade do suporte $(\mathrm{H} 1)$ quanto a qualidade da marca $(\mathrm{H} 2)$ seriam superiores nas franquias convencionais. Esse raciocínio foi guiado pelo fato das franquias convencionais exigirem maiores investimentos, com isso, o franqueador captaria mais recursos financeiros, permitindo-lhe investir mais intensamente nos processos operacionais e na marca da sua rede.

No que tange os resultados referentes à qualidade da marca, a confirmação desta hipótese remete a um entendimento da influência das marcas (brand equity) na percepção de valor dos franqueados. Torna-se nítida essa evidência, devido à maior inserção das franquias convencionais nos veículos de comunicação, sendo as marcas das microfranquias ainda desconhecidas de grande parte da sociedade. Tal aspecto pode ser constatado por meio da percepção de valor dos microfranqueados, que as adquirem acreditando no seu potencial como negócio, mesmo não se tratando de marcas conhecidas. Com isso, o microfranqueado, diante de recursos limitados para investimento, reconhece e aceita adquirir franquias sem marcas de renome.

Assim sendo, se por um lado os franqueados convencionais e os microfranqueados percebem de forma semelhante a qualidade do suporte recebido do franqueador, por outro entendem de forma não igualitária a qualidade da marca. Tem-se o que denominamos paradoxo do microfranqueado.

Uma das possíveis explicações para esse comportamento decorre do fato de que, em uma estrutura de microfranquia, que provavelmente conta com franqueados com nível de aprendizado e estrutura técnica inferior, faz com que reduzidos níveis de suporte do franqueador acarretem melhorias significativas em seu desempenho, ainda que esse suporte venha a ser menor do que o de uma franquia convencional. Dessa forma, pode-se deparar com o fato de que um suporte menor possa ser visto de forma igualitária entre franqueados convencionais e microfranqueados.

Esta questão soma-se à possibilidade de que exista uma sensação do microfranqueado de contar com uma marca inferior, fazendo-o se sentir em um patamar menor em termos de percepção de magnitude da franquia. Diante disto, ainda que o microfranqueado se perceba como pertencente a uma rede de franquias de marca mais fraca, esse sentimento de inferioridade pode levá-lo a valorizar mais um possível nível de suporte limitado recebido em relação ao franqueado convencional, que possui uma expectativa elevada desse suporte por parte do franqueador, por haver um maior investimento financeiro.

Assim, deduzimos que se pode ter um efeito de maior percepção de valor do nível de suporte recebido pelo microfranqueado em decorrência desse sentimento de pertencer a uma rede de franquia de marca inferior. Isto é, sentir-se mercadologicamente menor o faz valorizar de forma sobre-estimada o limitado suporte recebido, que não constava nas suas expectativas.

Denominamos de paradoxo do microfranqueado, no qual quanto menor o microfranqueado se sente em termos de mercado mais valor ele dá ao suporte recebido, já que este suporte se sobrepõe às suas expectativas dentro de uma inferioridade percebida pelo microfranqueado. Com isso, acreditamos que a percepção da qualidade do suporte recebido seria considerada igual em decorrência desta expectativa menor que uma marca mais fraca desperta no franqueado.

Portanto, como sugestões gerenciais, seria interessante que o microfranqueado recebesse do microfranqueador ou de entidades de suporte a pequenos negócios, como a Associação Brasileira de Franchising e o Sebrae, ensinamentos em forma de suporte, auxílio ou treinamentos sobre como realizar ações de marketing locais em sintonia com as políticas corporativas da rede de franquia. Isso 
significa criar e gerenciar suas próprias promoções, ações no ponto de venda, publicidade local, dentre outros.

Particularmente aos três estudos de casos complementares com os microfranqueados, caracterizou-se uma insatisfação com o suporte do franqueador. Esse resultado apresenta uma concordância com o nosso modelo teórico, e, de outro lado, uma contradição com os dados estatísticos testados. O que provavelmente pode ser compreendido pelo background desses microfranqueados.

Tanto o microfranqueado da rede A quanto o da B possuíam experiências prévias em negócios próprios (microfranqueados A e B) e em franquias (microfranqueado B), o que pode aumentar a exigência sobre o nível do suporte provido pelo franqueador. Entendemos que, por se possuir uma referência de comparação sobre o que é ter um negócio próprio, no qual não existe a figura do franqueador, o microfranqueado da rede A pode criar uma maior expectativa de entrega pelo franqueador desse suporte. Por sua vez, o microfranqueado da rede $\mathrm{B}$, já tendo a experiência prévia como franqueado, consegue comparar os níveis de suporte. Cabe mencionar que a rede à qual pertencia também era uma microfranquia, Kumon, o que pode demonstrar uma insatisfação particular com a rede atual, devido ao seu caráter ainda jovem como rede de franquias, ainda não tendo desenvolvido plenamente os mecanismos de franchising. Por fim, o microfranqueado $\mathrm{C}$ também entende que seu suporte recebido é deficitário, mas ela não tem qualquer experiência com negócio próprio para ter alguma base de comparação. Isto é, problemas existem nas microfranquias, assim como existem nas franquias convencionais. Pode-se entender isso pelo fato de que comumente os franqueadores não compreendem quais são as variáveis que agregam valor aos franqueados (Grace \& Weaven, 2011), ficando estes regularmente insatisfeitos com o suporte. Como as respondentes tinham relativamente pouca base de experiência para realizar uma comparação, é bastante provável que elas tenham experiências negativas, independente do que ocorre nas franquias convencionais.

Finalmente, no que se refere à marca das microfranquias, os entrevistados reafirmaram a nossa argumentação teórica e os resultados estatísticos. Há uma assertividade em reconhecer que as marcas de suas redes são inferiores, e que carecem de um melhor desenvolvimento pelo franqueador para o reconhecimento pelos consumidores. Em todos os casos, os microfranqueados entendem que a busca dos clientes pelo negócio se dá pela figura pessoal delas e não pela marca. Por isso, há um trabalho adicional a esses microfranqueados em conquistar a confiança do seu público alvo, pois não possuem marcas de destaque. Pelo fato das microfranquias serem percebidas pelos próprios microfranqueados como preteridas pelo público, corrobora-se com as teorias de que marcas maiores de franquias são preferidas pelo público (McAlister, Srinivasan, \& Kim, 2007; Singh, Faircloth, \& Nejadmalayeri, 2005).

\section{Conclusões}

Este artigo envolveu a comparação entre redes de franquias convencionais e redes de franquias que operam com o modelo de microfranquias, modelo de franquias que requerem um investimento inicial de até $\mathrm{R} \$ 50$ mil. Nessa comparação, analisaram-se as diferenças na percepção de valor do suporte e da marca pelo franqueado.

Os resultados estatísticos comprovaram que há diferenças na percepção de valor quanto à marca da rede de franquias. Nota-se o reconhecimento do microfranqueado que, mesmo considerando as microfranquias um negócio atraente e sem aparentemente considerar inferior o suporte fornecido pelo franqueador, reconhece que a marca da rede da qual faz parte é mais fraca do que a da franquia convencional.

Tais resultados chamam a atenção sobre como gerenciar e o que se pesquisar no ambiente das microfranquias. As diferenças apresentadas na percepção de valor dos franqueados quanto à marca de uma rede de franquias é um aspecto crítico, visto que a força de uma marca nesse modelo de negócio é 
um dos principais aspectos envolvidos no sistema de franchising responsável pela atratividade e pela retenção de franqueados e consumidores (Ghantous \& Jaolis, 2013; Nyadzayo et al., 2011).

Com isso, aponta-se primeiramente uma contribuição gerencial, chamando a atenção dos franqueadores que operam com microfranquias em melhor trabalharem os atributos da marca de suas microfranquias. Como sugestão, atributos relacionados à flexibilidade do local de trabalho e à adaptabilidade aos pequenos mercados talvez sejam características a serem vistas com empenho pelos microfranqueadores. Demonstrando que não é por serem pequenos, sejam faltosos em comprometimento, solidez e transparência, deixando de ter uma marca impactante no mercado onde tenham atuação. Aponta-se, por fim, para a necessidade em se ter flexibilidade para o microfranqueado trabalhar localmente suas ações de marketing para suprir a percepção de qualidade de marca inferiorizada, podendo ele reforçar a marca localmente.

Por seu turno, as contribuições acadêmicas demonstram uma complementação de conhecimento a um formato de franquias pouco pesquisado academicamente e que apresentam particularidades (Burand \& Koch, 2010; Fairbourne, 2006; Fairbourne et al., 2007; Ivins, 2008; Kistruck, Webb, Sutter, \& Ireland, 2011; Nghia, 2010; Oduor, Kamau, \& Mat, 2009). As contribuições acadêmicas residem em se ter gerado conhecimento sobre os seguintes elementos: (a) redes de microfranquias em operação no Brasil, um mercado emergente; (b) comparação entre franquias convencionais e microfranquias através de uma metodologia quantitativa, complementada com qualitativa; (c) percepções de valor dos franqueados sobre atributos essenciais do sistema de franchising como o suporte do franqueador e a marca de uma rede; e (d) mostrar que, no que tange a gestão de marketing, mais especificamente os requisitos da marca, as microfranquias precisam ser compreendidas e estudadas de maneira distinta das franquias convencionais, o que abre um campo de investigação para o aprofundamento do conhecimento das estratégias organizacionais do segmento de franchising.

Dentre as limitações desta pesquisa, apresentam-se o não tratamento estatístico com dados primários, o que limita a profundidade sobre os quesitos verificados neste artigo, havendo a complementaridade com três estudos de casos, que servem para sinalizar caminhos a serem aprofundados em estudos futuros. São casos específicos às suas realidades e que contam com microfranqueadas sem, relativamente, grandes experiências em franquias que podem ter uma visão comparativa para entender as especificidades de uma microfranquia. No mais, a compreensão do suporte ao franqueado restringiu-se à percepção de qualidade de três aspectos: treinamento, consultoria de campo e manual de operações. A variável marca limitou-se à percepção da qualidade referente à força da marca, à solidez e à transparência do franqueador. Mesmo havendo uma ampla literatura que suporte a questão da percepção de qualidade, esse conceito difere do nível de qualidade praticado (Chiou et al., 2004; Gupta \& Zeithaml, 2006). Tal aspecto não foi analisado neste estudo, dada a restrição metodológica e a indisponibilidade desse tipo de dado.

A segunda limitação identificada nesta pesquisa encontra-se na incapacidade dos dados analisados de propiciar a compreensão da origem das diferenças de percepção de valor entre os dois grupos de franqueados. Uma vez que as prerrogativas sobre o valor atribuído pelo franqueado podem ser influenciadas tanto pelo background do empreendedor quanto pelas práticas de gestão das redes de franquias.

Por outro lado, uma limitação amostral foi causada pela exclusão de um elevado número de redes de franquias que apresentavam dados faltantes devido às informações incompletas em pelo menos um dos anos analisados.

As sugestões de pesquisas futuras residem inicialmente em um maior aprofundamento sobre os aspectos envolvidos no suporte ao franqueado e os atributos da marca na concepção dos franqueados e franqueadores. Como segunda sugestão, acreditamos que seja relevante analisar tanto o background dos franqueados como a gestão dos franqueadores, a fim de melhor compreender a percepção de valor dos dois grupos de franqueados analisados neste estudo. Essa linha de estudo poderá contribuir para o 
limitado conhecimento que se possui internacionalmente sobre microempreendedores (Krishnan \& Kamalanabhan, 2013).

Finalmente, sugere-se verificar as estratégias de adoção de microfranquias por parte de redes que tradicionalmente operam com modelos convencionais de franquias, buscando compreender o porquê desse direcionamento, em uma abordagem, preferencialmente, qualitativa.

\section{Agradecimentos}

Agradecemos as contribuições dos pareceristas deste artigo, que nos forneceram orientações para o aprimoramento da nossa proposta de pesquisa. Adicionalmente, somos gratos aos microfranqueados que nos receberam e prestaram informações para estes casos.

\section{Referências}

Aaker, D. (1991). Managing brand equity. New York: The Free Press.

Aaker, D. (1996). Managing brand equity: capitalizing on the value of the brand name. New York: The Free Press.

Aqueveque, C. (2006). Extrinsic cues and perceived risk: the influence of consumption situation. Journal of Consumer Marketing, 23(5), 237-247. doi: 10.1108/07363760610681646

Associação Brasileira de Franchising. (2007). Guia oficial de franquias. São Paulo: Lamonica.

Associação Brasileira de Franchising. (2008). Guia oficial de franquias. São Paulo: Lamonica.

Associação Brasileira de Franchising. (2009). Guia oficial de franquias. São Paulo: Lamonica.

Associação Brasileira de Franchising. (2010). Guia oficial de franquias. São Paulo: Lamonica.

Associação Brasileira de Franchising. (2011). Guia oficial de franquias. São Paulo: Lamonica.

Associação Brasileira de Franchising. (2012). Guia oficial de franquias. São Paulo: Lamonica.

Associação Brasileira de Franchising. (2013). Guia de franquias: microfranquias. Recuperado de http://www.portaldofranchising.com.br/guia-de-franquias/microfranquias

Associação Brasileira de Franchising. (2014). Evolução do setor por segmento: acessórios pessoais e calçados. Recuperado de http://www.portaldofranchising.com.br/central/Content/UploadedFiles/Arquivos/Numeros-doFranchising-Evolucao-do-Setor-de-Franchising-2013.pdf

Bradach, J. (1997). Using the plural form in management of restaurant chains. Administrative Science Quartely, 42(2), 276-303. doi: 10.2307/2393921

Burand, D., \& Koch, D. (2010). Microfranchising: a business approach to fighting poverty. Franchise Law Journal, 30(1), 24-34.

Carney, M., \& Gedajlovic, E. (1991). Vertical integration in franchise systems: agency theory and resource explanations. Strategic Management Journal, 12(8), 607- 629. doi: $10.1002 / \mathrm{smj} .4250120804$ 
Carvalho, P., \& González, L. (2006). Modelo explicativo sobre a intenção empreendedora. Comportamento Organizacional e Gestão, 12(1), 43-60.

Castrogiovanni, G. J., Combs, J. G., \& Justis, R. T. (2006). Resource scarcity and agency theory predictions concerning the continued use of franchising in multi-outlet networks. Journal of Small Business Management, 44(1), 27-44. doi: 10.1111/j.1540-627X.2006.00152.x

Castrogiovanni, G. J., \& Justis, R. T. (2002). Strategic and contextual influences on firm growth: an empirical study of franchisors. Journal of Small Business Management, 40(2), 98-108. doi: 10.1111/1540-627X.00043

Chiou, J.-C., Hsieh, C.-H., \& Yang, C.-H. (2004). The effect of franchisors` communication, service assistance, and competitive advantage on franchisee intentions to remain in the franchise system. Journal of Small Business Management, 42(1), 19-36. doi: 10.1111/j.1540627X.2004.00095.x

Combs, J. G., \& Castrogiovanni, G. J. (1994). Franchisor strategy: a proposed model and empirical test of franchise versus company ownership. Journal of Small Business Management, 32(2), 3748 .

Combs, J. G., Michael, S. C., \& Castrogiovanni, G. J. (2004). Franchising: a review and avenues to greater theoretical diversity. Journal of Management, 30(6), 907-931. doi: 10.1016/j.jm.2004.06.006

Creswell, J. W. (2003). Research design. Qualitative, quantitative, and mixed methods approaches (2a ed.). Thousand Oaks: Sage.

Dant, R. P., Grünhagen, M., \& Windsperger, J. (2011). Franchising research frontiers for the twentyfirst century. Journal of Retailing, 87(3), 253-268. doi: 10.1016/j.jretai.2011.08.002

Dant, R. P., Perrigot, R., \& Cliquet, G. (2008). A cross-cultural comparison of the plural forms in franchise networks: USA, France, and Brazil. Journal of Small Business Management, 46(2), 286-311.

DelVecchio, D., \& Smith, D. C. (2005). Brand-extension price-premiums: the effect of perceived fit and extension product category risk. Journal of the Academy of Marketing Science, 33(2), 184196. doi: $10.1177 / 0092070304269753$

Elango, B. (2007). Are franchisors with international operations different from those who are domestic market oriented? Journal of Small Business Management, 45(2), 179-193. doi: 10.1111/j.1540627X.2007.00208.X

Erenkol, A., \& Duygun, A. (2010). Customers perceived brand equity and a research on the customers of Bellona which is a Turkish furniture brand. The Journal of American Academy of Business, 16(1), 34-42.

Fairbourne, J. S. (2006). Microfranchising: a new tool for creating economic self-reliance. Journal of Microfinance/ESR Review, 8(1), 18-26.

Fairbourne, J., Gibson, S., \& Dyer, W. (Eds.). (2007). Microfranchising: creating wealth at the bottom of the pyramid. Northampton, MA: Eward Elgar.

Falbe, C. M., \& Welsh, D. H. B. (1998). NAFTA and franchising: a comparison of franchisor perceptions of characteristics associated with franchisee success and failure in Canada, Mexico, and the United States. Journal of Business Venturing, 13(2), 151-171. doi: 10.1016/S08839026(97)00068-2 
Farmer, S., Yao, X., \& Kung-Mcintyre, K. (2011). The behavioral impact of entrepreneur identity aspiration and prior entrepreneurial experience. Entrepreneurship Theory and Practice, 35(2), 245-273. doi: 10.1111/j.1540-6520.2009.00358.x

Ghantous, N., \& Jaolis, F. (2013). Conceptualizing franchisee-based brand equity: a framework of the sources and outcomes of the brand's added value for franchisees. International Business Research, 6(2), 112. doi: 10.5539/ibr.v6n2p112

Grace, D., \& Weaven, S. (2011). An empirical analysis of franchisee value-in-use, investment risk and relational satisfaction. Journal of Retailing, 87(3), 366-380. doi: 10.1016/j.jretai.2010.06.001

Grünhagen, M., DiPietro, R. B., Stassen, R. E., \& Frazer, L. (2008). The effective delivery of franchisor services: a comparison of U.S. and German support practices for franchisees. Journal of Marketing Channels, 15(4), 315-335. doi: 10.1080/10466690802064034

Gupta, S., \& Zeithaml, V. (2006). Customer metrics and their impact on financial performance. Marketing Science, 25(6), 718-739. doi:10.1287/mksc.1060.0221

Hair, J. F., Black, W. C., Babin, B. J., Anderson, R. E., \& Tatham, R. L. (2009). Análise multivariada de dados (6a ed.). Porto Alegre: Bookman.

Harmon, T. R., \& Griffiths, M. A. (2008). Franchisee perceived relationship value. Journal of Business \& Industrial Marketing, 23(4), 256-263. doi: 10.1108/08858620810865834

Huang, Y.-A., \& Phau, I. (2009). Mapping the profiles of franchisees: getting to know the black sheep, rough diamonds, whingers and best buddies. Direct Marketing: An International Journal, 2(4), 221-238. doi: 10.1108/17505930810931026

Illetschko, K. (2011). Microfranchising: the theory. In N. Sireau (Eds.), Microfranchising: how social entrepreneurs are building a new road to development (Chap. 2, pp. 8-21). Sheffield: Greenleaf.

Ivins, T. (2008). Microfranchising microlearning centers: a sustainable model for expanding the right to education in developing countries? Journal of Asynchronous Learning Networks, 12(1), 27 35 .

Karnani, A. (2006). Mirage at the bottom of the pyramid: how the private sector can help alleviate poverty [Working paper $\mathrm{n}^{\circ}$ 835]. William Davidson Institute, University of Michigan, Ann Arbor, MI.

Kaufmann, P. J., \& Rangan, V. K. (1990). A model for managing system conflict during franchise expansion. Journal of Retailing, 66(2), 155-173.

Kim, H., Kim, W., \& An, A. (2003). The effect of consumer-based brand equity on firm`s financial performance. Journal of Consumer Marketing, 20(4), 335-351. doi: $10.1108 / 07363760310483694$

Kistruck, G. M., Webb, J. W., Sutter, C. J., \& Ireland, R. D. (2011). Microfranchising in base-of-thepyramid markets: institutional challenges and adaptations to the franchise model. Entrepreneuship Theory and Practice, 35(3), 503-531. doi: 10.1111/j.1540-6520.2011.00446.x

Krishnan, L., \& Kamalanabhan, T. (2013). Entrepreneurial success and life satisfaction among women entrepreneurs in micro enterprises. South Asian Journal of Management, 20(2), 40-63.

Krueger, A. B. (1991). Ownership, agency, and wages: an examination of franchising in the fast food industry. Quarterly Journal of Economics, 106(1), 75-101. doi: 10.2307/2937907 
Luce, M. S. (2013). Brasil: nova classe média ou novas formas de superexploração da classe trabalhadora? Revista Trabalho, Educação e Saúde, 11(1), 169-190. doi: 10.1590/S198177462013000100010

Mariz-Pérez, R., \& García-Álvarez, T. (2009). The internationalization strategy of Spanish indigenous franchised chains: a resource-based view. Journal of Small Business Management, 47(4), 514530. doi: 10.1111/j.1540-627X.2009.00281.x

McAlister, L., Srinivasan, R., \& Kim, M. (2007). Advertising, research and development, and systematic equity risk of the firm. Journal of Marketing, 71(1), 35-48.

Mcintyre, F., \& Huszagh, S. (1995). Internationalization of franchise systems. Journal of International Marketing, 3(4), 39-56.

Melo, P. L. R. de, \& Andreassi, T. (2010). Publicação científica nacional e internacional sobre franchising: levantamento e análise do período 1998-2007. Revista de Administração Contemporânea, $\quad 14(2), \quad 268-288 . \quad$ Recuperado de http://www.scielo.br/pdf/rac/v14n2/v14n2a06.pdf. doi: 10.1590/S1415-65552010000200006

Michael, S. C. (1999). Do franchised chains advertise enough? Journal of Retailing, 75(4), 461-478. doi: 10.1016/S0022-4359(99)00019-6

Monroy, M. F., \& Alzola, L. M. (2005). An analyses of quality management in franchise systems. European Journal of Marketing, 39(5/6), 585-605. doi: 10.1108/03090560510590728

Morgan, R., \& Hunt, S. (1994). The commitment-trust theory of relationship marketing. Journal of Marketing, 58(3), 20-38. doi: 10.2307/1252308

Munoz, J. M., Alon, I., \& Mitchell, M. C. (2010). Micro-franchising strategies: drawing lessons from franchising literature. In J. M. S. Munoz (Org.), Contemporary microenterprise. Concepts and cases (Cap. 13, pp. 155-179). Northhampton: Edward Elgar Publishing.

Neri, M. (2008). A nova classe média. Rio de Janeiro: FGV-IBRE, CPS, 2008. Recuperado de http://www.cps.fgv.br/cps/classe_media/

Neri, M. (2011). A nova classe média. São Paulo: Ed. Saraiva.

Nghia, N. (2010). Management research about solutions for the eradication of global poverty: a literature review. Journal of Sustainable Development, 3(1), 17-28.

Nijmeijer, K. J., Fabbricotti, I. N., \& Huijsman, R. (2014). Making franchising work: a framework based on a systematic review. International Journal of Management Reviews, 16(1), 62-83. doi: 10.1111/ijmr.12009

Nyadzayo, M. W., Matanda, M. J., \& Ewing, M. T. (2011). Brand relationship and brand equity in franchising. Industrial Marketing Management, 40(7), 1103-1115. doi: 10.1016/j.indmarman.2011.09.004

Oduor, J., Kamau, A., \& Mathenge, E. (2009). Evaluating the impact of microfranchising the distribution of anti-malarial drugs in Kenya on malaria mortality and morbidity. Journal of Development Effectiveness, 1(3), 353-377. doi: 10.1080/19439340903111855

Oxenfeldt, A., \& Kelly, A. (1968). Will successful franchise systems ultimately become whollyowned chains? Journal of Retailing, 44(1), 69-83.

Perryman, A. A., \& Combs, J. G. (2012). Who should own it? An agency-based explanation for multioutlet ownership and co-location in plural form franchising. Strategic Management Journal, 33(4), 368-386. doi: 10.1002/smj.1947 
Pitt, L., Napoli, J., \& Van Der Merwe, R. (2003). Managing the franchised brand: the franchisee's perspective. Journal of Brand Management, 10(6), 411-420.

Prahalad, C. (2004). The fortune at the bottom of the pyramid: eradicating poverty through profits. Upper Saddle River, NJ: Wharton School Publishing.

Pride, W., \& Ferrell, O. (2003). Marketing: concepts and strategies. Boston: Houghton Mifflin Company.

Rego, L. L., Billett, M. T., \& Morgan, N. A. (2009). Consumer-based brand equity and firm risk. Journal of Marketing, 73(6), 47-60. doi: 10.1509/jmkg.73.6.47

Revista Pequenas Empresas \& Grandes Negócios. (2007). Guia de franquias. Rio de Janeiro: Globo.

Revista Pequenas Empresas \& Grandes Negócios. (2008). Guia de franquias. Rio de Janeiro: Globo.

Revista Pequenas Empresas \& Grandes Negócios. (2009). Guia de franquias. Rio de Janeiro: Globo.

Revista Pequenas Empresas \& Grandes Negócios. (2010). Guia de franquias. Rio de Janeiro: Globo.

Revista Pequenas Empresas \& Grandes Negócios. (2011). Guia de franquias. Rio de Janeiro: Globo.

Revista Pequenas Empresas \& Grandes Negócios. (2012). Guia de franquias. Rio de Janeiro: Globo.

Seelos, C., \& Mair, J. (2007). Profitable business models and market creation in the context of deep poverty: a strategic view. Academy of Management Perspectives, 21(4), 49-63. doi: 10.5465/AMP.2007.27895339

Shane, S. A. (1996a). Hybrid organizational arragements and their implications for firm growth and survival: a study of new franchisors. Academy of Management Journal, 39(1), 216-234. doi: $10.2307 / 256637$

Shane, S. A. (1996b). Why franchise companies expand overseas. Journal of Business Venturing, 11(2), 73-88. doi: 10.1016/0883-9026(95)00110-7

Singh, M., Faircloth, S., \& Nejadmalayeri, A. (2005). Capital market impact of product marketing strategy: evidence from the relationship between advertising expenses and cost of capital. Journal of the Academy of Marketing Science, 33(4), 432-444. doi: 10.1177/0092070305277380

Vargo, S. L., \& Lusch, R. F. (2004b). Evolving to a new dominant logic for marketing. Journal of marketing, 66(1), 1-17. doi: 10.1509/jmkg.68.1.1.24036

Vargo, S. L., \& Lusch, R. F. (2004a). The four service marketing myths: remnants of a goods-based, manufacturing model. Journal of Service Research, 6(4), 324-335. doi: $10.1177 / 1094670503262946$

Whittaker, G., Ledden, L., \& Kalafatis, S. P. (2007). A re-examination of the relationship between value, satisfaction and intention in business services. Journal of Services Marketing, 21(5), 345357. doi: 10.1108/08876040710773651

Zeithaml, V. (1988). Consumer perceptions of price, quality, and value: a means-end model and synthesis of evidence. Journal of Marketing, 52(3), 2-22. doi: 10.2307/1251446 